\title{
Effect of feeding duration of Spirulina platensis on growth performance, haematological parameters, intestinal microbial population and carcass traits of broiler chicks
}

\author{
S. Sugiharto\#, T. Yudiarti, I. Isroli \& E. Widiastuti \\ Faculty of Animal and Agricultural Sciences, Diponegoro University, Semarang, Central Java, Indonesia (50275)
}

(Received 2 October 2017; Accepted 7 November 2017; First published online 16 November 2017)

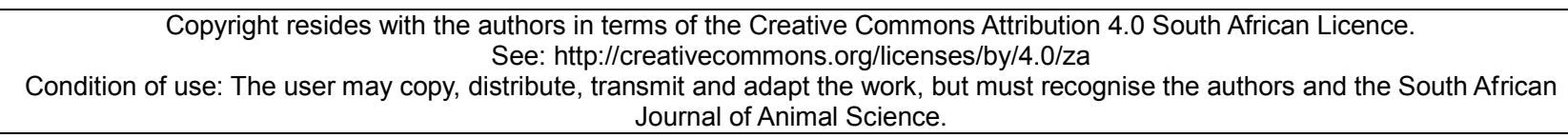

\begin{abstract}
Spirulina platensis is a good candidate as an in-feed antibiotics substitute for broilers. However, its use seems impractical owing to its high price, especially when being administered throughout the whole rearing period. This study aimed to investigate the effects of feeding duration of $S$. platensis on growth, haematological parameters, intestinal microbial population, and carcass traits of broiler chicks. A total of 288 one-day-old broiler chicks were randomly allotted to one of four groups, including control (basal diet with $0.04 \%$ zinc bacitracin) (CONT) and birds receiving basal diet supplemented with $1 \%$ of $S$. platensis for the first seven days (SP-7), for 21 days (SP-21), and for 35 days (SP-35). In this study, treatments had no significant effect on the growth performance of broilers. The caecum relative weight was significantly higher in SP-35 than in CONT and SP-21 birds. The values of haemoglobin, erythrocytes, and haematocrit were significantly lower in SP-35 than in other birds. Compared with CONT, SP-35 birds had significantly lower numbers of leukocytes, lymphocytes, and a lower number of eosinophils. The numbers of coliform were significantly lower in the ileum of SP-21 than in CONT and SP-7 birds. In the caecum, coliform tended to be lower in SP-21 than in other birds. There was no significant difference in the carcass traits of broilers across the groups. In conclusion, the administration of $S$. platensis for the first 21 days of broilers' life resulted in similar or even better responses than administration of $S$. platensis or in-feed antibiotics throughout the rearing period.
\end{abstract}

Keywords: Blood profile, bodyweight, broilers, carcass quality, feeding period, green alga, in-feed antibiotics \#Corresponding author: sgh_undip@yahoo.co.id

\section{Introduction}

To reach the maximum genetic potential for growth in broiler chickens, several nutritional strategies have been conducted, one of which is the use of antibiotics as feed additive (in-feed antibiotics). Sugiharto (2016) highlighted that in-feed antibiotics may be associated with improved growth and feed efficiency, as well as reduced morbidity and mortality in broiler production. However, owing to the development of antibiotic-resistant bacteria in humans and animals, the use of such additives was banned in most countries. Indeed, the withdrawal of synthetic antibiotics from broiler feeds led to performance and health problems in broiler chickens (Pourhossein et al., 2015; Sugiharto, 2016). For food safety reasons and sustainable broiler production, using alternatives to replace in-feed antibiotics for broilers was therefore crucial. Microalgae, for instance Chlorella vulgaris and Spirulina platensis, have recently attracted considerable interest among poultry nutritionists owing to their high nutritional and functional properties, which may be beneficial for broiler chickens (Jamil et al., 2015; Sugiharto \& Lauridsen, 2016). With regard to S. platensis in particular, this microalga has high contents of protein, essential amino acids, vitamins, minerals, essential fatty acids and pigments (Beheshtipour et al., 2013; Holman \& Malau-Aduli, 2013). Spirulina platensis is also rich in polysaccharides, which may function as prebiotics (Beheshtipour et al., 2013; de Jesus Raposo et al., 2016).

Several studies have demonstrated the growth-promoting effects of $S$. platensis on broiler chickens. Jamil et al. (2015) showed that feeding 2, 4, or $8 \mathrm{~g}$ of $S$. platensis/ $\mathrm{kg}$ feed increased and decreased the body weight and feed conversion ratio (FCR) of broiler chickens, respectively. Similar results were reported by Shanmugapriya et al. (2015a) when feeding $1 \%$ of S. platensis to broiler chicks. These authors revealed that 
such treatment resulted in increased villi height, and hence improved absorption capacity of broiler intestines. With regard to the health of chicks, S. platensis administration has been demonstrated to decrease the numbers of Escherichia coli and increase lactic acid bacteria (LAB) in the intestine of broilers (Shanmugapriya et al., 2015b). Concomitantly, Yusuf et al. (2016) reported an increased Lactobacilli population in the gut of Japanese quails with feeding S. platensis. In terms of immunity, earlier studies by Qureshi et al. (1996) and Raju et al. (2004) reported that feeding S. platensis enhanced the humoral and cellular immune responses and lymphoid organ development of chicks. Recently, Lokapirnasari et al. (2016) showed that treatment with $S$. platensis increased the number of leukocytes and decreased the mortality rate of broiler chicks. In their review, Farag et al. (2016) pointed out that the antimicrobial and immunomodulatory (and anti-inflammatory) capacities as well as antioxidant potential seemed to be responsible for the healthpromoting effect of $S$. platensis on poultry. As well as growth and health performances, treatment with $S$. platensis was reported to increase carcass percentage and ready-to-cook yields of broiler chicks in the studies of Raju et al. (2004), Kaoud (2012) and Holman \& Malau-Aduli (2013). Moreover, Bonos et al. (2016) showed that Spirulina supplementation $(5 \mathrm{~g} / \mathrm{kg})$ was capable of improving the meat quality of broiler, that is, increasing the contents of eicosapentaenoic acid (EPA), docosapentaenoic acid (DPA) and docosahexaenoic acid (DHA) in the thigh muscles of broiler chicks. Taken together, S. platensis seems to have potential to replace the role of antibiotics in broiler diets.

As an alternative to in-feed antibiotics, $S$. platensis has commonly been administered to broiler diets from day of hatch to slaughter age (Qureshi et al., 1996; Jamil et al., 2015; Bonos et al., 2016). Compared with antibiotics and other broiler feed ingredients, S. platensis is more expensive (Holman \& Malau-Aduli, 2013). Apart from its benefits, the application of Spirulina as the replacement for in-feed antibiotics in broiler production therefore seems impractical, especially when used throughout the rearing period. For this reason, poultry nutritionists should reconsider the feeding duration of $S$. platensis to reduce the amount and cost of the microalga used in broiler production. With regard to probiotics, Pietras (2001) found no effect of feeding duration (that is, from days 1 to 21 , from days 22 to 49 and from days 1 to 49 old) of probiotic Lactobacillus acidophilus and Streptococcus faecium on the production variables of broilers. In the current study, $S$. platensis was administered in broiler feeds for various durations within the rearing period. The objective of this study was therefore to investigate the effects of feeding duration of $S$. platensis on growth performance, haematological parameters, intestinal microbial population and carcass traits of broiler chicks.

\section{Materials and methods}

Two hundred and eighty-eight Lohmann (MB-202) one-day-old broiler chicks (bodyweight $42.0 \pm 0.22$ g) (means \pm standard deviation) were used in the current study. The chicks were randomly distributed to one of four groups of 72 chicks each ( 6 replicates of 12 chicks). Throughout the study period, the chicks were raised in an open-sided broiler house with rice husk-littered floor pens. The treatment groups included control birds (birds receiving basal diet with $0.04 \%$ zinc bacitracin) (CONT) and birds receiving basal diets supplemented with $1 \%$ of $S$. platensis for the first seven days (SP-7), for 21 days (SP-21), and for 35 days (SP-35). The proportion of $S$. platensis supplemented to basal diets was based on Shanmugapriya et al. (2015a). Feeds (as mash form) and water were provided ad libitum throughout the study period. A coccidiostat was not included in the feeds. The chemical compositions of $S$. platensis powder and basal diets (formulated to meet the Indonesian National Standards for Broiler Feed (SNI, 2006)) provided to broiler chicks are presented in Tables 1 and 2, respectively. Zinc bacitracin or S. platensis was added at the expense of the feeds. S. platensis was obtained from PT. Neoalga Indonesia Makmur (Sukoharjo, Central Java, Indonesia). The microalgae were grown in fresh water. The experiment was conducted according to the standard procedures of rearing and treating of farm animals as stated in law of the Republic of Indonesia, number 18, 2009, concerning animal husbandry and health.

Table 1 Chemical composition of Spirulina platensis (as-dry basis)

\begin{tabular}{lc}
\hline Items & Composition (\%) \\
\hline Moisture & 91.8 \\
Crude ash & 11.9 \\
Crude fat & 0.63 \\
Crude protein & 52.4 \\
Crude fibre & 34.2 \\
\hline
\end{tabular}


Table 2 Ingredients and nutrient composition (as-dry basis) of basal diet used in the study

\begin{tabular}{|c|c|}
\hline Items & Composition (\%, unless otherwise noted) \\
\hline Maize & 45.5 \\
\hline Soybean meal (CP 46\%) & 17.0 \\
\hline Wheat flour & 10.0 \\
\hline Bread flour & 5.00 \\
\hline Rice bran & 4.45 \\
\hline Crude palm oil & 3.50 \\
\hline Corn gluten meal (CP 62\%) & 3.60 \\
\hline Distiller dried grains (CP 27\%) & 3.00 \\
\hline Meat bone meal (CP 49\%) & 2.80 \\
\hline Chicken feather meal (CP 79\%) & 2.00 \\
\hline Bone meal (CP 22\%) & 1.50 \\
\hline Lysine & 0.55 \\
\hline Methionine & 0.37 \\
\hline L-threonine & 0.08 \\
\hline Salt & 0.15 \\
\hline Premix $^{1}$ & 0.50 \\
\hline \multicolumn{2}{|l|}{ Analysed composition: } \\
\hline Metabolizable energy $(\mathrm{kcal} / \mathrm{kg})^{2}$ & 3,300 \\
\hline Dry matter & 89.6 \\
\hline Crude protein & 21.9 \\
\hline Crude fat & 6.40 \\
\hline Crude fiber & 5.62 \\
\hline Ash & 6.39 \\
\hline
\end{tabular}

${ }^{1}$ Mineral-vitamin premix per kg of diet: Ca 2.250 g, P 0.625 g, Fe 3.570 mg, Cu 0.640 mg, Mn 5.285 mg, Zn 0.003 mg, Co $0.001 \mathrm{mg}$, Se $0.013 \mathrm{mg}$, I $0.016 \mathrm{mg}$, vit A $375 \mathrm{IU}$, vit D $150 \mathrm{IU}$ and vit E $0.080 \mathrm{mg}$

${ }^{2}$ Metabolizable energy was calculated according to formula (Bolton, 1967 ): $40.81\{0.87$ (crude protein +2.25 crude fat + nitrogen-free extract) +2.5 )

$\mathrm{CP}$ : crude protein

The chicks were vaccinated with commercial Newcastle disease virus (NDV) vaccine through eye drops and drinking water at days 4 and 18 of the experiment, respectively. Bodyweight and feed intake were determined weekly. The FCR was determined as the feed intake per weight gain. To determine haematological profile, blood was obtained from the wing veins and collected in vacutainers containing ethylenediaminetetraacetic acid (EDTA) at day 32. The rest of the blood was collected in the vacutainers with no anticoagulant, let to clot at room temperature, and centrifuged at $2000 \mathrm{rpm}$ for 15 minutes to produce serum. The serum was frozen until analyses of antibody titres and serum biochemistry (Sugiharto et al., 2017a). At day 35, a total of 24 chicks were slaughtered, de-feathered and eviscerated. The internal organs were immediately taken out and weighed. Digesta were collected from the ileum and caecum of broilers to determine $\mathrm{pH}$ and for microbiological analyses.

Complete blood counts were determined using a hematology analyser (Prima Fully Auto Hematology Analyser, PT. Prima Alkesindo Nusantara, Jakarta, Indonesia). The NDV antibody titers of serum were determined based on haemagglutination inhibition (HI) assay (Villegas, 1987). The titers were presented as geometric mean titers $\left(\log _{2}\right)$. Total triglyceride, total cholesterol, high-density lipoprotein (HDL) and lowdensity lipoprotein (LDL) cholesterol and uric acid in serum were measured with the enzymatic colorimetric/colour method. Total protein, albumin, alanine aminotransferase (ALT), and aspartate aminotransferase (AST) in serum were determined with spectrophotometric/photometric tests. Data of globulin were obtained from the difference between the values of total protein and albumin in serum. The counts of certain bacteria in the intestinal digesta of broilers were determined according to Sugiharto et al. 
(2017b) with few modifications. For enumeration of coliform bacteria and lactose-negative enterobacteria, samples were cultured on MacConkey agar. After aerobic incubation at $38^{\circ} \mathrm{C}$ for $24 \mathrm{~h}$, coliform and lactosenegative enterobacteria were counted as red and colourless colonies, respectively. The sum of coliform bacteria and lactose-negative enterobacteria was defined as enterobacteria. Lactic acid bacteria (LAB) were determined on de Man, Rogosa and Sharpe (MRS) agar after anaerobic incubation at $38^{\circ} \mathrm{C}$ for $48 \mathrm{~h}$.

Data were analysed based on a completely randomized design by ANOVA using the General Linear Models Procedure in SAS (SAS Inst. Inc., Cary, NC, USA). Pen was treated as the experimental unit. Significant differences among treatment groups were further analysed using Duncan's multiple-range test. A significant level of $P<0.05$ was implemented.

\section{Results}

Data on the performances of broilers are presented in Table 3. There was a tendency for CONT birds to have higher $(P=0.05)$ weight gain for the first week of rearing compared with other birds. On days 22 to 35 , FCR was lower $(P<0.05)$ in SP-21 birds than in CONT and SP-7 birds, but not different when compared with that in SP-35 birds. For the entire rearing period (days 0 to 35$)$, no difference $(P>0.05)$ was observed with regard to weight gain, feed intake and FCR of broiler chicks.

Table 3 Effect of feeding duration of Spirulina platensis on performances of broiler chicks (means and SE)

\begin{tabular}{lcccccc}
\hline \multirow{2}{*}{ Items (g) } & \multicolumn{7}{c}{ Treatments } & \multirow{2}{*}{ SE } & P value \\
\cline { 2 - 4 } & CONT & SP-7 & SP-21 & SP-35 & & \\
Weight gain & & & & & \\
Days 0-7 & 135 & 118 & 112 & 122 & 5.54 & 0.05 \\
Days 8-21 & 635 & 636 & 642 & 632 & 11.3 & 0.93 \\
Days 22-35 & 1,000 & 984 & 1,048 & 1,018 & 26.5 & 0.37 \\
Days 0-35 & 1,770 & 1,737 & 1,803 & 1,771 & 35.2 & 0.64 \\
Feed intake & & & & & \\
Days 0-7 & 151 & 148 & 145 & 151 & 2.26 & 0.20 \\
Days 8-21 & 970 & 968 & 976 & 970 & 9.31 & 0.95 \\
Days 22-35 & 1,712 & 1,688 & 1,665 & 1,689 & 32.6 & 0.79 \\
Days 0-35 & 2,833 & 2,804 & 2,786 & 2,811 & 33.9 & 0.80 \\
FCR & & & & & \\
Days 0-7 & 1.14 & 1.26 & 1.29 & 1.25 & 0.04 & 0.09 \\
Days 8-21 & 1.53 & 1.52 & 1.52 & 1.54 & 0.02 & 0.90 \\
Days 22-35 & $1.72^{\mathrm{a}}$ & $1.72^{\mathrm{a}}$ & $1.60^{\mathrm{b}}$ & $1.66^{\mathrm{ab}}$ & 0.03 & 0.04 \\
Days 0-35 & 1.60 & 1.62 & 1.55 & 1.59 & 0.02 & 0.19 \\
\hline
\end{tabular}

${ }^{a, b}$ Means with different superscripts in each row are significantly different

CONT: birds receiving basal diet with $0.04 \%$ of zinc bacitracin, SP-7: birds receiving $1 \%$ of $S$. platensis for the first seven days, SP-21: birds receiving $1 \%$ of S. platensis for the first 21 days, SP-35: birds receiving $1 \%$ of S. platensis for 35 days, FCR: feed conversion ratio, SE: standard error

Table 4 shows the data on internal organs of broiler chicks. The relative weight of the caecum was higher $(P<0.05)$ in SP-35 than CONT and SP-21 birds, but the difference was not substantial when compared with SP-7 birds. There were no significant differences in other internal organs of birds.

Data on haematological parameters of broiler chicks are presented in Table 5 . The values of haemoglobin, erythrocytes and haematocrit were lower $(P<0.05)$ in SP-35 than in other birds. The numbers of leukocytes and lymphocytes were lower $(P<0.05)$ in SP-35 than in CONT birds, but the difference was not pronounced when compared with that in SP-7 and SP-21 birds. Concomitantly, the number of eosinophils tended $(P=0.07)$ to be lower in SP-35 than in CONT birds. The serum biochemical parameters and antibody titer against NDV were not different $(P>0.05)$ across the treatment groups. 
Table 4 Effect of feeding duration of Spirulina platensis on internal organs of broiler chicks (means and SE)

\begin{tabular}{lcccccc}
\hline \multirow{2}{*}{ Items (\% live body weight) } & \multicolumn{4}{c}{ Treatments } & \multirow{2}{*}{ SE } & P value \\
\cline { 2 - 4 } & CONT & SP-7 & SP-21 & SP-35 & & \\
\hline Heart & 0.51 & 0.51 & 0.46 & 0.45 & 0.03 & 0.28 \\
Liver & 2.41 & 2.61 & 2.43 & 2.40 & 0.16 & 0.77 \\
Proventriculus & 0.46 & 0.48 & 0.47 & 0.46 & 0.02 & 0.92 \\
Gizzard & 1.31 & 1.16 & 1.13 & 1.29 & 0.06 & 0.11 \\
Pancreas & 0.28 & 0.29 & 0.25 & 0.26 & 0.02 & 0.36 \\
Duodenum & 0.51 & 0.52 & 0.47 & 0.48 & 0.03 & 0.68 \\
Jejunum & 0.98 & 1.01 & 1.09 & 1.04 & 0.08 & 0.79 \\
lleum & 0.68 & 0.79 & 0.74 & 0.76 & 0.09 & 0.84 \\
Caecum & $0.26^{\mathrm{b}}$ & $0.27^{\mathrm{ab}}$ & $0.24^{\mathrm{b}}$ & $0.32^{\mathrm{a}}$ & 0.02 & 0.03 \\
Spleen & 0.10 & 0.12 & 0.13 & 0.13 & 0.03 & 0.82 \\
Thymus & 0.38 & 0.42 & 0.30 & 0.34 & 0.05 & 0.28 \\
Bursa of Fabricius & 0.14 & 0.16 & 0.12 & 0.17 & 0.02 & 0.34 \\
& & & & & & \\
\hline
\end{tabular}

\footnotetext{
${ }^{a, b}$ Means with different superscripts in each row are significantly different

CONT: birds receiving basal diet with $0.04 \%$ of zinc bacitracin, SP-7: birds receiving $1 \%$ of S. platensis for the first seven days; SP-21: birds receiving $1 \%$ of S. platensis for the first 21 days; SP-35: birds receiving $1 \%$ of S. platensis for 35 days; SE: standard error
}

The numbers of coliform bacteria were lower $(P<0.05)$ in the ileal digesta of SP-21 than in CONT and SP-7 birds, but the difference was not significant when compared with that in SP-35 birds (Table 6). In accordance, there was a tendency $(P=0.08)$ for the lower number of coliform bacteria in caecal digesta of SP-21 than in other birds. There were no differences $(P>0.05)$ in the numbers of lactose negativeenterobacteria, enterobacteria and LAB both in the ileum and caecum of broiler chicks.

Data on carcass traits of broiler chicks are presented in Table 7. In general, there was no difference ( $P$ $>0.05)$ in the carcass traits of broilers.

\section{Discussion}

A number of studies have revealed the consistent benefits of $S$. platensis on the growth and health performances of broiler chickens (Qureshi et al., 1996; Raju et al., 2004; Kaoud, 2012; Jamil et al., 2015; Shanmugapriya et al., 2015a; Lokapirnasari et al., 2016; Yusuf et al., 2016). Based on these published data, the authors inferred that $S$. platensis could be an alternative to in-feed antibiotics for broiler chickens. With the focus on replacing synthetic antibiotics in feed, the periods during which $S$. platensis was administered in broiler feeds were compared with solely antibiotics-supplemented feed. Hence, the authors did not provide an unsupplemented (neither with antibiotics nor S. platensis) feed group (as negative control) in the present study. The present results showed that the period during which $S$. platensis was supplemented in broiler feed did not affect growth performance of broilers. This finding was similar to that of Pietras (2001), which showed no effect of feeding duration of probiotic Lactobacillus acidophilus and Streptococcus faecium on production parameters of broiler chickens. Irrespective of feeding duration, dietary supplementation with $1 \%$ of $S$. platensis resulted in a corresponding effect on the growth performance when compared with feeding zinc bacitracin as a growth promoter to broilers. Indeed, inclusion of $1 \%$ of $S$. platensis in the diets for the first 21 days improved FCR of broilers during days 22 to 35 . Taken together, the current data may confirm the efficacy of $S$. platensis as an alternative to antibiotics in broiler diets.

In this study, feeding $S$. platensis for the entire rearing period enhanced the relative weight of caecum of broilers. The heavier caecum may be associated with the improved fermentation function of broiler chicks (Clench \& Mathias, 1995). The definite explanation for the enhanced weight of caecum in broilers fed $S$. platensis for 35 days was not known, but it was possible that long-term feeding of $S$. platensis led to greater fibre intake, and thus resulted in heavier caeca (Moen et al., 2016). Note that $S$. platensis in this study contained $34.2 \%$ of fibre. 
Table 5 Effect of feeding duration of Spirulina platensis on haematological parameters of broiler chicks (means and SE)

\begin{tabular}{|c|c|c|c|c|c|c|}
\hline \multirow{2}{*}{ Items } & \multicolumn{4}{|c|}{ Treatments } & \multirow{2}{*}{ SE } & \multirow{2}{*}{$P$ value } \\
\hline & CONT & SP-7 & SP-21 & SP-35 & & \\
\hline \multicolumn{7}{|l|}{ Complete blood counts } \\
\hline Haemoglobin (g/dL) & $9.78^{\mathrm{a}}$ & $10.2^{\mathrm{a}}$ & $10.3^{\mathrm{a}}$ & $7.78^{\mathrm{b}}$ & 0.57 & 0.02 \\
\hline Erythrocytes $\left(10^{6} / \mu \mathrm{L}\right)$ & $2.30^{\mathrm{a}}$ & $2.30^{\mathrm{a}}$ & $2.39^{a}$ & $1.82^{b}$ & 0.11 & 0.01 \\
\hline Hematocrit (\%) & $30.2^{\mathrm{a}}$ & $31.0^{\mathrm{a}}$ & $31.9^{\mathrm{a}}$ & $24.8^{\mathrm{b}}$ & 1.59 & 0.02 \\
\hline $\operatorname{MCV}(\mathrm{fl})$ & 131 & 135 & 134 & 138 & 1.51 & 0.11 \\
\hline $\mathrm{MCH}(\mathrm{pg})$ & 42.6 & 44.2 & 42.8 & 41.9 & 1.28 & 0.63 \\
\hline $\mathrm{MCHC}(\mathrm{g} / \mathrm{dL})$ & 32.5 & 32.8 & 32.0 & 30.7 & 0.93 & 0.39 \\
\hline Leukocytes $\left(10^{3} / \mu \mathrm{L}\right)$ & $22.2^{\mathrm{a}}$ & $17.1^{\mathrm{ab}}$ & $16.8^{\mathrm{ab}}$ & $13.4^{b}$ & 2.04 & 0.04 \\
\hline Heterophils $\left(10^{3} / \mu \mathrm{L}\right)$ & 0.63 & 0.55 & 0.47 & 0.42 & 0.12 & 0.58 \\
\hline Eosinophils $\left(10^{3} / \mu \mathrm{L}\right)$ & 0.92 & 0.65 & 0.73 & 0.57 & 0.09 & 0.07 \\
\hline Lymphocytes $\left(10^{3} / \mu \mathrm{L}\right)$ & $20.7^{\mathrm{a}}$ & $15.9^{\mathrm{ab}}$ & $15.6^{\mathrm{ab}}$ & $12.5^{\mathrm{b}}$ & 1.89 & 0.04 \\
\hline \multicolumn{7}{|l|}{ Biochemical parameters } \\
\hline Total cholesterol (mg/dL) & 128 & 146 & 150 & 139 & 7.65 & 0.23 \\
\hline $\mathrm{HDL}(\mathrm{mg} / \mathrm{dL})$ & 64.2 & 54.5 & 57.2 & 64.5 & 11.3 & 0.88 \\
\hline LDL (mg/dL) & 46.5 & 67.2 & 75.1 & 61.6 & 11.7 & 0.39 \\
\hline Total triglyceride (mg/dL) & 73.2 & 148 & 95.8 & 127 & 37.6 & 0.48 \\
\hline AST (U/L) & 204 & 236 & 247 & 254 & 25.2 & 0.52 \\
\hline $\operatorname{ALT}(\mathrm{U} / \mathrm{L})$ & 7.63 & 6.52 & 3.00 & 7.57 & 1.82 & 0.25 \\
\hline Total protein (g/dL) & 2.76 & 2.90 & 2.90 & 3.13 & 0.13 & 0.28 \\
\hline Albumin (g/dL) & 1.25 & 1.22 & 1.32 & 1.25 & 0.05 & 0.60 \\
\hline Globulin (g/dL) & 1.56 & 1.68 & 1.58 & 1.88 & 0.13 & 0.29 \\
\hline $\mathrm{A} / \mathrm{G}$ ratio & 0.81 & 0.73 & 0.86 & 0.70 & 0.06 & 0.22 \\
\hline Uric acid (mg/dL) & 5.73 & 5.99 & 8.05 & 7.29 & 1.62 & 0.68 \\
\hline Antibody titer against NDV ( $\log _{2}$ GMT) & 3.50 & 3.00 & 3.00 & 4.67 & 0.57 & 0.16 \\
\hline
\end{tabular}

${ }^{a, b}$ Means with different superscripts in each row are significantly different

CONT: birds receiving basal diet with $0.04 \%$ of zinc bacitracin; SP-7: birds receiving $1 \%$ of $S$. platensis for the first seven days; SP-21: birds receiving 1\% of S. platensis for the first 21 days; SP-35: birds receiving $1 \%$ of $S$. platensis for 35 days; MCV: mean corpuscular volume; $\mathrm{MCH}$ : mean corpuscular hemoglobin; MCHC: mean corpuscular hemoglobin concentration; HDL: high-density lipoprotein; LDL: low-density lipoprotein; AST: aspartate aminotransferase; ALT: alanine aminotransferase; A/G ratio: albumin to globulin ratio; NDV: Newcastle disease virus; GMT: geometric mean titer; SE: standard error

Dietary supplementation of $S$. platensis has been reported to increase the number of erythrocytes and haemoglobin in broiler chicks (Jamil et al., 2015). In contrast, feeding such algae during the whole rearing period resulted in lower values of erythrocytes, haemoglobin and haematocrit of broilers in the current study. To date, the cause of this decrease is not known, but long-term exposure of broilers to $S$. platensis may have a negative effect on the liver, where erythrocytes and haemoglobin are partly produced. Indeed, Iwasa et al. (2002) showed the presence of hepatotoxin (microcystin) in Spirulina, which may cause liver disruptions. Concomitantly, Roy-Lachapelle et al. (2017) found cyanotoxins in Spirulina that may induce liver problems. However, the authors' inference should be interpreted with caution as there was no significant impact of various feeding durations of $S$. platensis on the indicators of liver disruptions (e.g. AST, ALT and the relative liver weight). In parallel with the erythrocyte profile, the numbers of leukocytes, lymphocytes and eosinophils were lower in birds supplemented with $S$. platensis during the rearing period. These findings were different from those reported by Jamil et al. (2015) and Lokapirnasari et al. (2016), which showed increased leukocytes with feeding $S$. platensis in broiler chicks. Again, the liver disruptions owing to long-term exposure to toxins in $S$. platensis seemed to contribute to the lower leukocytes and the differential leukocytes of 
broilers in the present study. Interesting data were seen in the study of Shanmugapriya et al. (2015a), at which feeding $1.5 \%$ of Spirulina resulted in lower final bodyweight when compared with feeding 0.5 or $1 \%$ of S. platensis. Perhaps, excessive intake of $S$. platensis resulted in metabolic disturbances and affected the liver function leading to retarded growth rate in broilers. Considering the contradictory results between our study and others negatively, the differences in nutritional and functional properties of $S$. platensis used in the studies may to some extent be responsible. Note that $S$. platensis used in the current study was grown in fresh water, not in sea water as is the common commercial S. platensis available in the market.

Table 6 Effect of feeding duration of Spirulina platensis on intestinal microbial populations of broiler chicks (means and SE)

\begin{tabular}{|c|c|c|c|c|c|c|}
\hline \multirow{2}{*}{ Items (log cfu/g) } & \multicolumn{4}{|c|}{ Treatments } & \multirow{2}{*}{ SE } & \multirow{2}{*}{$P$ value } \\
\hline & CONT & SP-7 & SP-21 & SP-35 & & \\
\hline \multicolumn{7}{|l|}{ lleum } \\
\hline Coliform & $6.80^{\mathrm{a}}$ & $6.74^{\mathrm{a}}$ & $6.09^{b}$ & $6.51^{a b}$ & 0.16 & 0.03 \\
\hline Lactose negative-enterobacteria & 1.56 & 1.64 & 2.17 & 1.67 & 1.02 & 0.97 \\
\hline Enterobacteria & 8.36 & 8.37 & 8.26 & 8.18 & 1.03 & 0.99 \\
\hline LAB & 8.77 & 8.87 & 8.75 & 8.73 & 0.19 & 0.96 \\
\hline \multicolumn{7}{|l|}{ Caecum } \\
\hline Coliform & 6.32 & 6.21 & 5.79 & 6.44 & 0.19 & 0.08 \\
\hline Lactose negative-enterobacteria & 4.59 & 4.20 & 4.33 & 4.83 & 0.64 & 0.90 \\
\hline Enterobacteria & 10.9 & 10.4 & 10.1 & 11.3 & 0.61 & 0.56 \\
\hline $\mathrm{LAB}$ & 8.73 & 8.78 & 8.66 & 8.84 & 0.13 & 0.80 \\
\hline
\end{tabular}

${ }^{a, b}$ Means with different superscripts in each row are significantly different

CONT: birds receiving basal diet with $0.04 \%$ of zinc bacitracin; SP-7: birds receiving $1 \%$ of S. platensis for the first seven days; SP-21: birds receiving $1 \%$ of S. platensis for the first 21 days; SP-35: birds receiving $1 \%$ of S. platensis for 35 days; LAB: lactic acid bacteria; SE: standard error

Table 7 Effect of feeding duration of Spirulina platensis on carcass traits of broiler chicks (means and SE)

\begin{tabular}{|c|c|c|c|c|c|c|}
\hline \multirow{2}{*}{ Items } & \multicolumn{4}{|c|}{ Treatments } & \multirow{2}{*}{ SE } & \multirow{2}{*}{$P$ value } \\
\hline & CONT & SP-7 & SP-21 & SP-35 & & \\
\hline \multicolumn{7}{|c|}{ (\% live weight) } \\
\hline Giblet $^{1}$ & 4.23 & 4.29 & 4.02 & 4.14 & 0.19 & 0.76 \\
\hline Eviscerated carcass & 67.9 & 69.4 & 69.3 & 68.7 & 0.62 & 0.28 \\
\hline \multicolumn{7}{|c|}{ (\% eviscerated carcass) } \\
\hline Breast & 36.3 & 34.3 & 35.7 & 35.6 & 0.81 & 0.40 \\
\hline Thigh & 15.9 & 15.8 & 16.3 & 15.5 & 0.52 & 0.77 \\
\hline Drumstick & 13.5 & 13.1 & 13.4 & 13.8 & 0.45 & 0.78 \\
\hline Wing & 10.7 & 10.9 & 10.6 & 11.0 & 0.41 & 0.88 \\
\hline Abdominal fat & 2.43 & 2.22 & 2.46 & 1.99 & 0.26 & 0.56 \\
\hline
\end{tabular}

Giblet: heart, gizzard and liver

CONT: birds receiving basal diet with $0.04 \%$ of zinc bacitracin; SP-7: birds receiving $1 \%$ of $S$. platensis for the first seven days; SP-21: birds receiving 1\% of S. platensis for the first 21 days; SP-35: birds receiving $1 \%$ of S. platensis for 35 days; SE: standard error

In the present study, feeding $1 \%$ of $S$. platensis, especially during the first 21 days, decreased the numbers of coliform in the ileal and caecal digesta of broiler chicks. This finding was in accordance with that 
reported by Shanmugapriya et al. (2015b), which showed the decreased E. coli population in the ileal and caecal digesta of broilers when feeding $1 \%$ of S. platensis. In the study of Yusuf et al. (2016), it was apparent that feeding $2 \%$ of $S$. platensis decreased the numbers of coliform bacteria in the ileocecal contents of Japanese quails fed a vegetarian protein diet. Concomitantly, Nuhu (2013) showed the bacterial clearance capacities of S. platensis in chicks injected with E. coli or Staphylococcus aureus. In such cases, the antimicrobial activities (against pathogenic bacteria) of $S$. platensis seemed to be responsible. In their in vitro study, Mala et al. (2009) showed that extract of S. platensis was able to inhibit the growth of Klebsiella pneumoniae, Shigella shigae, E. coli, S. aureus, Proteus vulgaris, Pseudomonas aeruginosa and Salmonella typhi. Similar to this, Kaushik \& Chauhan (2008) showed the antibacterial activities of $S$. platensis against $S$. aureus and E. coli, while El-Baz et al. (2013) showed the antibacterial activities of S. platensis extract against E. coli, S. aureus, S. typhi, and Enterococcus faecalis. Indeed, several compounds, including Ylinolenic acid, active fatty acid lauric and palmitoleic acid, have been attributed to the antimicrobial activities of S. platensis (El-Sheekh et al., 2014). With its prebiotic properties (Beheshtipour et al., 2013; de Jesus Raposo et al., 2016), S. platensis is known to possess a stimulating effect on the growth of LAB (Lactobacillus acidophilus, Lactobacillus casei and Streptococcus thermophilus) (Bhowmik et al., 2009). In broiler chickens, S. platensis administration has been associated with the increased intestinal population of LAB (Shanmugapriya et al., 2015b), while in Japanese quails, feeding such algae tended to increase the count of intestinal lactobacilli (Yusuf et al., 2016). Unlike these earlier studies, treatment with S. platensis in the present study did not affect the ileal and caecal populations of LAB. To date, the explanation for these divergent data remains unclear, but the different levels and the nutritional qualities of $S$. platensis as well as the trial conditions may be responsible.

Several studies reported that feeding S. platensis increased carcass percentage of broiler chicks (Raju et al., 2004; Kaoud, 2012; Mariey et al., 2014) and Japanese quails (Jamil et al., 2015). In contrast, the present findings did not show any effect of $S$. platensis (regardless of feeding duration) on carcass traits of broilers. The data of the current study were concomitant with those reported by Cheong et al. (2016), which showed no significant effect of feeding up to $8 \%$ of $S$. platensis on the carcass, breast and legs percentage of Japanese quails. No substantial effect on the carcass weight was seen in rabbit, as reported by Mahmoud et al. (2017) when including S. platensis to replace soybean in the diets of rabbits (with percentage of 20, 40 and $60 \%$ ). The precise reason for these different results is not known, but the relatively similar final bodyweight may result in the similar carcass percentage of broilers among the treatment groups in the present study. This inference was supported by Mariey et al. (2014), who suggested that carcass weight was in parallel with the live body weight of broilers. That is, the increased carcass weight and total edible part were attributed to the increased final live bodyweight of broilers, and vice versa.

\section{Conclusion}

From the present study, it can be concluded that the administration of $S$. platensis for the first 21 days of broiler's lives resulted responses that were similar to or better than administration of $S$. platensis or antibiotics throughout the entire rearing period. It is therefore not necessary to administer $S$. platensis throughout the rearing period to obtain antibiotic-like benefits for broilers.

\section{Acknowledgements}

The study was funded by the Faculty of Animal and Agricultural Sciences, Diponegoro University through the Faculty Research Grant No: 84/UN7.5.5/PP/2017, 18 May 2017

\section{Authors' Contributions}

SS designed the study, carried out the animal experiment, data analysis and manuscript drafting. II and EW carried out the animal experiment. TY conducted the laboratory analysis.

\section{Conflict of Interest Declaration}

The authors declare that they have no competing interests.

\section{References}

Beheshtipour, H., Mortazavian, A.M., Mohammadi, R., Sohrabvandi, S. \& Khosravi-Darani, K., 2013. Supplementation of Spirulina platensis and Chlorella vulgaris algae into probiotic fermented milks. Compr. Rev. Food Sci. Food Saf. 12, 144-154.

Bhowmik, D., Dubey, J. \& Mehra, S., 2009. Probiotic efficiency of Spirulina platensis-stimulating growth of lactic acid bacteria. American-Eurasian J. Agric. \& Environ. Sci. 6, 546-549.

Bolton, W., 1967. Poultry nutrition. MAFF Bulletin No.174. HMSO, London.

Bonos, E., Kasapidou, E., Kargopoulos, A., Karampampas, A., Christaki, E., Florou-Paneri, P. \& Nikolakakis, I., 2016. Spirulina as a functional ingredient in broiler chicken diets. S. Afr. J. Anim. Sci. 46, 94-102. 
Cheong, D.S.W., Kasim, A., Sazili, A.Q., Omar, H. \& Teoh, J.Y., 2016. Effect of supplementing Spirulina on live performance, carcass composition and meat quality of Japanese quail. Walailak J. Sci. Tech. 13, 77-84.

Clench, M.H. \& Mathias, J.R., 1995. The avian cecum: a review. Wilson Bull. 107, 93-121.

de Jesus Raposo, M.F., de Morais, A.M.M.B. \& de Morais, R.M.S.C., 2016. Emergent sources of prebiotics: seaweeds and microalgae. Mar. Drugs. 14, 27; doi:10.3390/md14020027

El-Baz, F.K., El-Senousy, W.M., El-Sayed, A.B. \& Kamel, M.M., 2013. In vitro antiviral and antimicrobial activities of Spirulina platensis extract. J. Appl. Pharm. Sci. 3, 52-56.

El-Sheekh, M.M., Daboor, S.M., Swelim, M.A. \& Mohamed, S., 2014. Production and characterization of antimicrobial active substance from Spirulina platensis. Iran. J. Microbiol. 6, 112-119.

Farag, M.R., Alagawany, M., El-Hack, M.E.A. \& Dhama, K., 2016. Nutritional and healthical aspects of Spirulina (Arthrospira) for poultry, animals and human. Int. J. Pharmacol. 12, 36-51.

Holman B.W.B. \& Malau-Aduli, A.E.O., 2013. Spirulina as a livestock supplement and animal feed. J. Anim. Physiol. Anim. Nutr. 97, 615-623.

Iwasa, M., Yamamoto, M., Tanaka, Y., Kaito, M. \& Adachi, Y., 2002. Spirulina associated hepatotoxicity. Am. J. Gastroenterol. 97, 3212-3213.

Jamil, A.B.M.R., Akanda, R., Rahman, M., Hossain, A. \& Islam, S., 2015. Prebiotic competence of spirulina on the production performance of broiler chickens. J. Adv. Vet. Anim. Res. 2, 304-309.

Kaoud, H.A., 2012. Effect of Spirulina platensis as a dietary supplement on broiler performance in comparison with prebiotics. Sci. J. App. Res. 1, 44-48.

Kaushik, P. \& Chauhan, A., 2008. In vitro antibacterial activity of laboratory grown culture of Spirulina platensis. Indian J. Microbiol. 48, 348-352.

Lokapirnasari, W.P., Yulianto, A.B., Legowo, D. \& Agustono, 2016. The effect of Spirulina as feed additive to myocardial necrosis and leukocyte of chicken with avian influenza (H5N1) virus infection. Proc. Chem.18, 213-217.

Mahmoud, A.E., Naguib, M.M., Higazy, A.M., Sultan, Y.Y. \& Marrez, D.A., 2017. Effect of substitution soybean by blue green alga Spirulina platensis on performance and meat quality of growing rabbits. Am. J. Food Technol. 12, 5159.

Mala, R., Sarojini, M., Saravanababu, S. \& Umadevi, G., 2009. Screening for antimicrobial activity of crude extracts of Spirulina platensis. J. Cell Tissue Res. 9, 1951-1955.

Mariey, Y.A., Samak, H.R., Abou-Khashba, H.A., Sayed, M.A.M. \& Abou-Zeid, A.E., 2014. Effect of using Spirulina platensis algae as a feed additives for poultry diets: 2-Productive performance of broiler. Egypt. Poult. Sci. 34, 245-258.

Moen, B., Henjum, K., Måge, I., Knutsen, S.H., Rud, I., Hetland, R.B. \& Paulsen, J.E., 2016. Effect of dietary fibers on cecal microbiota and intestinal tumorigenesis in azoxymethane treated A/J Min/+ mice. PLoS ONE. 11, e0155402. https://doi.org/10.1371/journal.pone.0155402

Nuhu, A.A., 2013. Spirulina (Arthrospira): An important source of nutritional and medicinal compounds. J. Marine Biol. http://dx.doi.org/10.1155/2013/325636

Pietras, M., 2001. The effect of probiotics on selected blood and meat parameters of broiler chickens. J. Anim. Feed Sci. 10, 297-302.

Pourhossein, Z., Qotbi, A.A.A., Seidavi, A., Laudadio, V., Centoducati, G. \& Tufarelli, V., 2015. Effect of different levels of dietary sweet orange (Citrus sinensis) peel extract on humoral immune system responses in broiler chickens. Anim. Sci. J. 86, 105-110.

Qureshi, M.A., Garlich, J.D. \& Kidd, M.T., 1996. Dietary Spirulina platensis enhances humoral and cell-mediated immune functions in chickens. Immunopharmacol. Immunotoxicol. 18, 465-476.

Raju, M.V.L.N., Rama Rao, S.V., Radhika, K. \& Chawak, M.M., 2004. Effects of Spirulina platensis or furazolidone on the performance and immune response of broiler chickens fed with aflatoxin contaminated diet. Indian J. Anim. Nutr. $21,40-44$.

Roy-Lachapelle, A., Solliec, M., Bouchard, M.F. \& Sauvé, S., 2017. Detection of cyanotoxins in algae dietary supplements. Toxins. 9, 76; doi:10.3390/toxins9030076

SAS Institute, Inc., 1985. SAS user's guide: Statistics, version 5. Cary, NC, USA.

Shanmugapriya, B., Babu, S.S., Hariharan, T., Sivaneswaran, S., Anusha, M.B. \& Raja, P.U., 2015a. Synergistic effect of Spirulina platensis on performance and gut microbial load of broiler chicks. Indo-Asian J. Multidisc. Res. 1, 149155.

Shanmugapriya, B., Babu, S.S., Hariharan, T., Sivaneswaran, S. \& Anusha, M.B., 2015b. Dietary administration of Spirulina platensis as probiotics on health and histopathology in broiler chicks. Int. J. Recent Sci. Res. 6, 26502653.

SNI (Indonesian National Standard), 2006. Standard for broiler feed (SNI 01-3930-2006). National Standardization Agency of Indonesia, Jakarta, Indonesia (article in Bahasa).

Sugiharto, S., 2016. Role of nutraceuticals in gut health and growth performance of poultry. J. Saudi Soc. Agric. Sci. 15, 99-111.

Sugiharto, S. \& Lauridsen, C., 2016. Dietary Chlorella supplementation effect on immune responses and growth performances of broiler chickens exposed to post hatch holding time. Livest. Res. Rur. Dev. 28; http://www.Irrd.org//rrd28/7/sugi28119.html

Sugiharto, S., Yudiarti, T., Isroli, I., Widiastuti, E. \& Putra, F.D., 2017a. Intestinal microbial ecology and hematological parameters of broiler fed cassava waste pulp fermented with Acremonium charticola, Vet. World. 10, 324-330. 
Sugiharto, S., Yudiarti, T., Isroli, I., Widiastuti, E. \& Putra, F.D., 2017b. Effect of dietary supplementation with Rhizopus oryzae or Chrysonilia crassa on growth performance, blood profile, intestinal microbial population, and carcass traits in broilers exposed to heat stress. Arch. Anim. Breed., 60, 347-356.

Villegas, P., 1987. Avian virus diseases laboratory manual. College of Veterinary Medicine. University of Georgia, Athens, Georgia, USA.

Yusuf, M.S., Hassan, M.A., Abdel-Daim, M.M., El Nabtiti, A.S., Ahmed, A.M., Moawed, S.A., El-Sayed, A.K. \& Cui, H., 2016. Value added by Spirulina platensis in two different diets on growth performance, gut microbiota, and meat quality of Japanese quails. Vet. World. 9, 1287-1293. 